\title{
Rapid, minimally invasive adult voluntary male circumcision: A randomised trial of Unicirc, a novel disposable device
}

\author{
P S Millard, ${ }^{1} \mathrm{MD}$, PhD; H R Wilson, ${ }^{2} \mathrm{BA}$; N D Goldstuck, ${ }^{3} \mathrm{MB}$ BCh; C Anaso, ${ }^{4} \mathrm{MB}$ ChB \\ ${ }^{1}$ Graduate Program in Public Health, University of New England, Portland, Maine, USA \\ ${ }^{2}$ Department of Pediatrics, New York University, New York, USA \\ ${ }^{3}$ Department of Obstetrics and Gynaecology, Faculty of Medicine and Health Sciences, Stellenbosch University and Tygerberg Hospital, Cape Town, South Africa \\ ${ }^{4}$ Simunye Primary Health Care, Mitchells Plain, Western Cape, South Africa
}

Corresponding author: P S Millard (pmillard@mac.com)

\begin{abstract}
Background. Voluntary medical male circumcision (VMMC) is a priority HIV preventive intervention. To facilitate VMMC scale-up, the World Health Organization is seeking circumcision techniques that are faster, easier, and safer than open surgical methods.

Objective. To compare open surgical circumcision with suturing v. the Unicirc disposable instrument plus tissue adhesive.

Methods. We conducted a non-blinded randomised controlled trial at an outpatient primary healthcare clinic in Cape Town, South Africa, with 2:1 allocation ratio of 150 male volunteers who were at least 18 years of age. Our primary outcome was intraoperative time and secondary outcomes were ease of performance, post-operative pain, adverse events, time to healing, patient satisfaction and cosmetic result. Results. The intraoperative time was less with the Unicirc/adhesive technique (median $13 \mathrm{v} .22 .6$ min, respectively; $p<0.001$ ). The intraoperative suturing rate was $17 \%$ using the Unicirc device. Other adverse events and wound healing outcomes were similar in both groups, but the cosmetic result was superior in the Unicirc group. Doctors found the Unicirc procedure easier to perform and preferred it to the open surgical technique. Conclusions. This study has important implications for the scale-up of VMMC services. Excising the foreskin with the Unicirc instrument and sealing the wound with cyanoacrylate tissue adhesive in adults is quicker, easier to learn, and is potentially safer than open surgical VMMC. Further studies should be conducted with the optimised device. This new instrument has the potential to facilitate more rapid scale-up and save costs.
\end{abstract}

S Afr Med J 2014;104(1):52-57. DOI:10.7196/SAMJ.7357

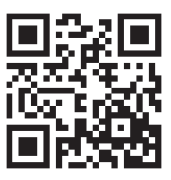

Voluntary medical male circumcision (VMMC) reduces female-to-male transmission of HIV by $38 \%$ to $66 \%$ over 24 months $^{[1]}$ and is a priority preventive intervention for the World Health Organization $(\mathrm{WHO})^{[2]}$ and the US President's Emergency Plan for AIDS Relief (PEPFAR). ${ }^{[3]}$ In South Africa (SA), the national strategic plan for 2012 to 2016 calls for circumcising $80 \%$ of men between 15 and 49 years of age ( 4.3 million men). If this goal is met, more than 1 million new HIV infections can be averted with overall net savings of US $\$ 5.5$ billion between 2011 and 2025. ${ }^{[4]}$ Thus far, the health department is behind on its target and is unlikely to achieve these goals unless additional modalities can help to scale up the medical circumcision process. ${ }^{[5]}$

Open surgery with suturing is the standard technique currently used in most VMMC programmes. Unfortunately, it is time-consuming, requires good surgical skills, and minor complications are common under the programmatic conditions existing in Africa. ${ }^{[6]}$ We have previously shown that VMMC using the Gomco instrument to excise the foreskin and sealing the wound with tissue adhesive is faster, easier, and has superior cosmetic results compared with open surgical circumcision. ${ }^{[7]}$

\section{Objective}

To compare conventional open surgical circumcision with suturing to a minimally invasive technique using a single-use-only disposable instrument (Unicirc) plus tissue adhesive. This technique completes the circumcision at the time of surgery, and requires no further visits for device removal. We hypothesised that the new technique would be superior to open surgical VMMC with regard to intraoperative time, ease of performance, and have similar adverse events.

\section{Methods \\ Trial design}

This was a single-centre non-blinded randomised controlled trial with 2:1 (Unicirc:surgical) allocation ratio in balanced blocks of 15, following the guidelines of the WHO Framework for Clinical Evaluation of Devices for Adult Male Circumcision. ${ }^{[8]}$ An investigator (HRW), who was not involved in the surgeries, allocated participants in a 2:1 ratio in blocks of 15 using a random number table. Slips of paper with the group assignment were folded and placed in sealed, opaque envelopes. Each envelope was opened only at the time of surgery. We used the sample size recommended in the WHO Framework. ${ }^{[8]}$ The sample size of 150 (50 surgical and 100 Unicirc) gave us $>90 \%$ power to detect a mean difference of $8 \mathrm{~min}$ in duration of surgery.

The South African Medical Association's Ethics Committee (SAMAREC) approved the study. The ClinicalTrials.gov identifier is NCT01877408. All subjects gave informed consent. The study took place between 21 June and 8 August 2013.

\section{Participants}

Healthy uncircumcised men of at least 18 years of age were eligible for the study. Participants were recruited via posters at two affiliated primary healthcare clinics in Cape Town, SA.

Exclusion criteria were concurrent illness, history of bleeding disorder, past reaction to local anaesthetic, infection, or penile abnormality that would complicate circumcision. Men with complete phimosis were excluded from the study, but we included men with partial phimosis without adhesions. We included men with scarring of the frenulum, because it is a common condition easily corrected at the time of circumcision. 
Participants received HIV prevention counselling. We offered HIV testing, but did not request testing as a study prerequisite. The ethics panel advised us not to require a test for HIV (and therefore exclude HIV-positive men), because this was a study of a surgical procedure, not a study of whether or not circumcision prevents HIV. Participants were advised to abstain from sexual intercourse until the wound was completely healed and for at least 4 weeks after the circumcision. Condoms were made freely available.

\section{Intervention}

Four generalist doctors, assisted by registered nurses, performed the circumcisions in individual consultation rooms in a single primary healthcare clinic on four different dates.

We used a mixture of $2 \%$ lidocaine with marcaine local anaesthesia as a subcutaneous ring block at the base of the penis as per the WHO Manual for Male Circumcision under Local Anaesthesia. ${ }^{[9]}$

One of the following interventions was performed:

- Open surgical technique. We used the dorsal slit technique, the sleeve technique, or the forceps-guided technique according to doctor preference as described in the WHO manual..$^{[9]}$ After suturing, the wound was covered with an absorbent gauze dressing.

- Unicirc with cyanoacrylate skin adhesive. The Unicirc is a plastic and metal single-use-only disposable instrument designed in SA. The instruments were gas sterilised in sealed packages. After applying the Unicirc instrument to the foreskin, we waited 5 min before excising the foreskin with a surgical scalpel. We then removed the instrument and sealed the apposed skin-mucosal edges with cyanoacrylate skin adhesive. We used four different Unicirc sizes in this study: $2.6 \mathrm{~cm}$, $2.9 \mathrm{~cm}, 3.2 \mathrm{~cm}$ and $3.5 \mathrm{~cm}$. We covered the wound with an adherent tape (Hypafix) and absorbent gauze. We removed the absorbent gauze at the two-day follow-up visit, and instructed participants to keep the wound dry and to leave the adherent tape in place for two weeks.

All men were observed for $20 \mathrm{~min}$ after the procedure. Subjects were given written post-operative instructions and cellular telephone contact information of the doctor.

\section{Outcome measures}

- Primary. Intraoperative time.

- Secondary. Doctor-described ease in performing the technique, estimated blood loss, complications (operative and post-operative), post-operative pain, time to healing, patient satisfaction, cosmetic result, and direct costs of expendable materials.

- Key adverse events considered were anaesthetic complications, bleeding, haematoma, infection, wound disruption, problems with urination, subsequent procedures conducted to correct complications, and occupational exposure to blood and body fluids. We used standardised definitions to grade adverse events as mild, moderate or severe, using the WHO Framework for Clinical Evaluation of Devices for Adult Male Circumcision. ${ }^{[8]}$ In brief, adverse events were categorised as mild if they required little or no intervention (e.g. mild wound disruption or slight bleeding), moderate if they required active treatment (e.g. antibiotics or suturing), or severe if they required transfusion or hospitalisation, or resulted in permanent damage.

- Costs. Direct costs of expendable material.

Outcome definitions are shown in our previous publication. ${ }^{[7]}$ Wound healing outcomes were assessed by the principal investigator (PSM), a co-author (NG) and one of the surgeons (Dr Senzo Ntshalintshali).

\section{Follow-up}

Follow-up was at 2 days, 7 days, 2 weeks, and 4 weeks. For those men who were not completely healed by 4 weeks, we conducted an additional 6-week follow-up visit.

\section{Data analysis}

We collected data from participants on socio-demographics and circumcision knowledge/attitudes, and from participating doctors on ease of performing the surgery. We used a 10-point visual analogue scale for pain evaluation in the first $48 \mathrm{~h}$ after circumcision and a 5-point Likert scale to grade satisfaction.

We conducted: (i) analysis of baseline data to examine potential confounders; (ii) calculation of descriptive statistics of outcomes; and (iii) statistical tests of operative time, differences in scale (e.g. 5-point Likert and 10-point pain scale) and proportions. We analysed the data with Epi Info (version 7).

\section{Results \\ Participant flow}

We recruited participants from 31 May to 26 June 2013. The flow of participants in the study is shown in Fig. 1. A total of 184 men were interviewed and 150 (81.5\%) participated in the study. All participants were circumcised using the method to which they were randomly allocated.

\section{Baseline data}

The baseline characteristics of the participants are shown in Table 1. The majority of men gave improved hygiene as their motivation for circumcision, $5 \%$ cited reduction in infections. There were no significant differences in the baseline characteristics of the two groups.

\section{Outcomes analysed}

Operative outcomes are shown in Table 2; 17 (17\%) of the Unicirc circumcisions required intraoperative suturing. Intraoperative time and blood loss (without frenulectomy) were less with the Unicirc/tissue adhesive technique, median 13 v. $22.6 \mathrm{~min}(p<0.001)$, respectively, and median 1 v. $5.5 \mathrm{ml}(p<0.001)$, respectively.

Adverse events are shown in Table 3 . There were no significant differences between the two groups in bleeding, haematoma or infection. Wound disruptions $>2 \mathrm{~cm}$ occurred in $2(2 \%)$ of the Unicirc circumcisions at one week, and $1(1 \%)$ at 2 weeks. Wound disruptions were $<5 \mathrm{~mm}$ in width, and none required surgical closure.

Post-operative pain, healing time, participant satisfaction and cosmetic results are shown in Table 4. Post-operative pain scores were low in both groups. There were no differences in healing at 4 weeks or in patient satisfaction. All subjects were fully healed at 6 weeks. The cosmetic result was superior in the Unicirc group; a regular scar line was found in $80.6 \%$ of the Unicirc subjects v. $40.0 \%$ in the surgical group $(p<0.001)$.

\section{Cost of expendable material}

For the surgical VMMCs, we used pre-sterilised disposable kits specified by the WHO in SA at a cost of US\$15. For the Unicirc VMMCs, we used pre-sterilised disposable kits that did not contain sutures or suturing instruments, at a cost of US $\$ 4$, and a single-use tube of tissue adhesive at US $\$ 5$. The Unicirc device cost US\$20. The other costs (e.g. local anaesthesia, bandages) were similar for the two methods.

The results from the doctors' survey are shown in Table 5. Doctors found the Unicirc procedure easier to perform and preferred it to the open surgical technique. Three of the four doctors had significant 


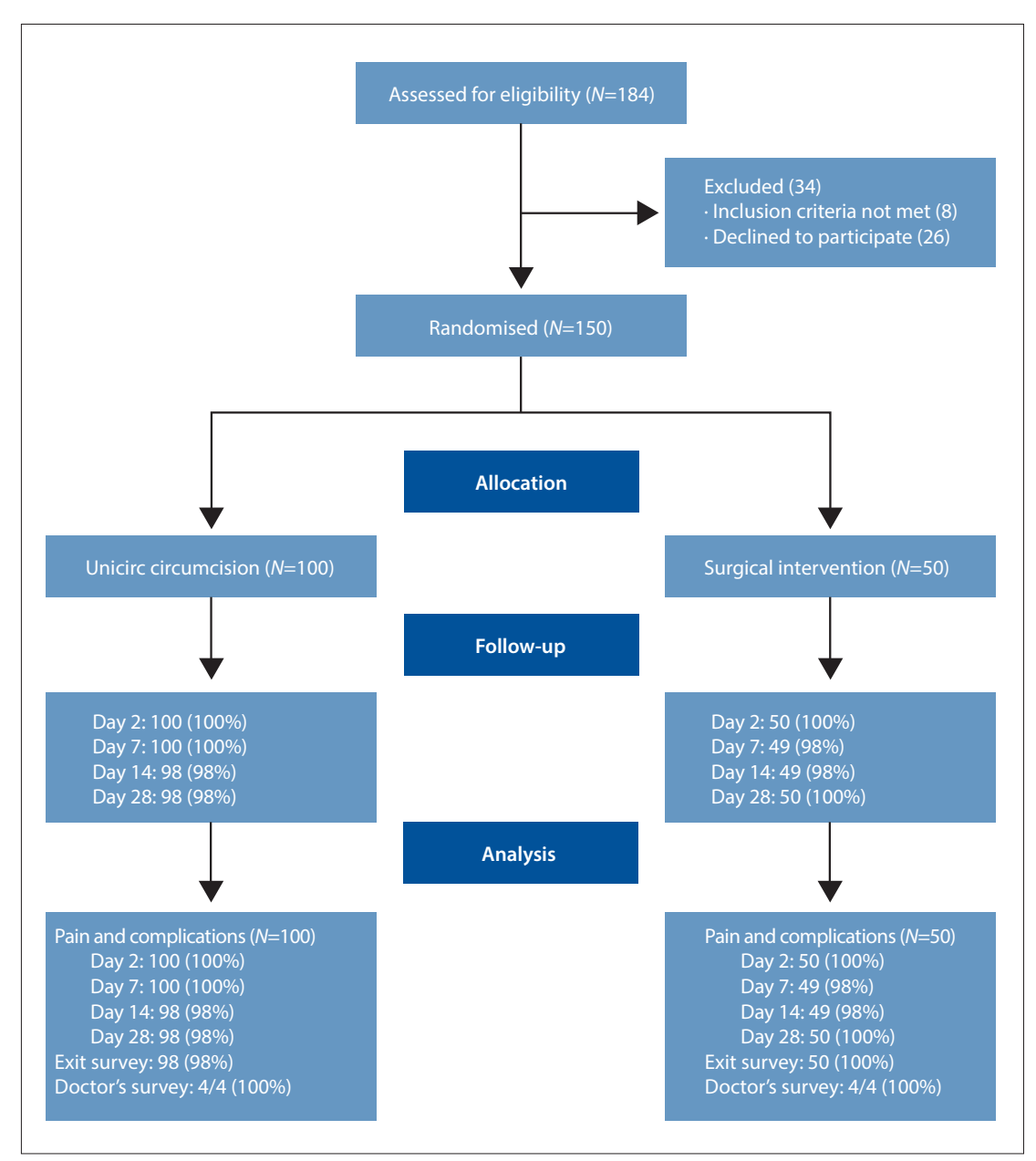

Fig. 1. Participant flow diagram.

previous experience performing open surgical circumcisions. Among these three doctors, there were two glove perforations during the study. One experienced doctor cut himself with a scalpel while doing an open surgical circumcision. The doctor with limited prior experience reported $>10$ glove perforations during the study.

\section{Discussion}

Circumcision scale-up in sub-Saharan Africa has been constrained by the time needed and technical difficulties of performing open surgical circumcision, the only method approved by PEPFAR. To more effectively scale-up services, we require fundamental improvements in current circumcision techniques. We need techniques that are rapid, easy to learn, performed with standard instruments, inexpensive, result in few complications, and provide excellent patient satisfaction and cosmetic results.

New VMMC modalities - plastic rings which all share common characteristics - have recently received a great deal of publicity. ${ }^{[5]}$ They are attractive because they require less skill to place and are more rapid than is re-usable and sterilisable. Given that the Gomco instrument consists of three different parts, mismatching parts from different-sized instruments or different manufacturers may potentially cause complications.

The Unicirc shares the advantages of the Gomco instrument, but it overcomes the above drawbacks. It is a metal and plastic instrument that is designed with threads that self-destruct after a single use, definitively preventing re-use. Because it is pre-packaged, mismatching of parts is not an issue.

The generalist doctors in this study were moderately experienced in open surgical circumcision but had not previously used the Gomco or Unicirc instruments. Operative times were much shorter with Unicirc v. surgical VMMC (13 v. $22.6 \mathrm{~min}$, respectively). Using the WHO Models for Optimizing the Volume and Efficiency (MOVE) of task-sharing, ${ }^{[14]}$ the actual time savings should be much greater than is reflected by this difference. It takes 1 2 min to place the instrument, and 2 - 3 min to excise the foreskin, remove the instrument and apply the adhesive. The $5 \mathrm{~min}$ of waiting time while the compressive action takes place could be well used in other tasks. The time savings using the Unicirc/adhesive technique are likely to substantially reduce overall cost and assist in mass scale-up.

There were no serious adverse events in this study, and post-operative complications were similar in the two groups. However, $17 \%$ of the Unicirc subjects required intraoperative suturing, and there was a non-significant trend toward increased post-operative bleeding and haematoma with Unicirc. All post-operative bleeding occurred while the subjects were still in the clinic under post-operative supervision. Nonetheless, it was not an anticipated or desirable result and we did not find this in our prior experience with the prototype Unicirc device. We attribute the bleeding to shrinkage that occurred after the injection moulding of the plastic component of the Unicirc production instruments used in this study.

We subsequently made minor revisions to the device to increase the compressive forces. After approval by SAMAREC, we conducted a further 50 Unicirc circumcisions in volunteers who had expressed an interest in the original study. None of the participants required intraoperative suturing, and we found a low rate of post-operative bleeding and haematoma with the revised Unicirc device (Table 6).

Unlike our previous study conducted during the rainy season in an impoverished community in Mozambique, adhesive failure was not a problem in this cohort. The SA participants had much more success in keeping the wound adhesive dry in the post-operative period. The inexpensive, Asian-manufactured 
Table 1. Baseline characteristics

\begin{tabular}{|c|c|c|}
\hline & $\begin{array}{l}\text { Unicirc/adhesive } \\
(N=100), n \text { and } \%\end{array}$ & $\begin{array}{l}\text { Open surgical }{ }^{*} \\
(N=50), n(\%)\end{array}$ \\
\hline \multicolumn{3}{|l|}{ Age (years) } \\
\hline $18-25$ & 21 & $12(24)$ \\
\hline $36-35$ & 49 & $21(42)$ \\
\hline$\geq 36$ & 30 & $17(34)$ \\
\hline \multicolumn{3}{|l|}{ Marital status } \\
\hline Single (in a relationship) & 38 & $26(52)$ \\
\hline Married & 53 & $17(34)$ \\
\hline No partner & 9 & $7(14)$ \\
\hline \multicolumn{3}{|l|}{ Religion } \\
\hline Christian & 74 & $33(66)$ \\
\hline Muslim & 16 & $6(12)$ \\
\hline No religion & 10 & $11(22)$ \\
\hline \multicolumn{3}{|l|}{ Education level } \\
\hline Primary & 5 & $2(4)$ \\
\hline Secondary & 91 & $45(90)$ \\
\hline Post-secondary & 4 & $3(6)$ \\
\hline \multicolumn{3}{|l|}{$\begin{array}{l}\text { Reason for wanting } \\
\text { circumcision }\end{array}$} \\
\hline Hygiene & 76 & $33(66)$ \\
\hline Reduce infections & 5 & $3(6)$ \\
\hline Social/religious & 16 & $8(16)$ \\
\hline Other & 3 & $6(12)$ \\
\hline
\end{tabular}

Table 2. Intraoperative outcomes

\begin{tabular}{lll}
\hline & $\begin{array}{l}\text { Unicircl } \\
\text { adhesive } \\
(N=100)\end{array}$ & $\begin{array}{l}\text { Open surgical } \\
(N=50)\end{array}$ \\
\hline $\begin{array}{l}\text { Intraoperative suturing, } n(\%) \\
\text { Frenulectomy performed, } n(\%)\end{array}$ & $17(17)$ & All by protocol \\
$\begin{array}{l}\text { Intraoperative time (min), } \\
\text { median (IQR) }\end{array}$ & $6(12)$ \\
$\quad$ With frenulectomy & $28.6(17.7)$ & $25(18)$ \\
$\quad$ Without frenulectomy & $13(4.5)$ & $22.6(8.6)$ \\
$\begin{array}{l}\text { Estimated blood loss (ml), } \\
\text { median (IQR) }\end{array}$ & & \\
$\quad$ With frenulectomy & $6.5(3.5)$ & $10(6.5)$ \\
$\quad$ Without frenulectomy & $1(1)$ & $5.5(6.5)$ \\
$\begin{array}{l}\text { IQR }=\text { interquartile range. } \\
{ }_{p} 00.001 .\end{array}$ & &
\end{tabular}

cyanoacrylate adhesive that we used was more difficult to apply because it had a lower viscosity than the cyanoacrylate adhesive that we used in our Mozambique study. In future studies, it would be worthwhile to compare the performance of other cyanoacrylate formulations.

The cost of expendable materials was similar using the two techniques. The cost of tissue adhesive approximates the cost of suture materials. Unicirc requires fewer disposable instruments (only one haemostat and one scalpel) and this nearly compensated for the cost of the Unicirc device. Because the Unicirc procedure requires no follow-up visits, we expect there to be significant cost savings compared with plastic ring devices, such as the Shang Ring and PrePex. Plastic ring devices also require both an application pack and a removal pack, which contains scissors and a device for removing the ring.

There were several glove perforations among doctors during the study, and one doctor injured himself with a scalpel. Because the Unicirc/ adhesive technique requires no sutures, there is no possibility of a needlestick injury from a suture needle. All doctors preferred the Unicirc method to the surgical method, citing ease of performance and shorter intraoperative time as advantages of the Unicirc.

No one technique will be suitable for all settings. The Unicirc/tissue adhesive procedure is ideal for outpatient settings, where large numbers of circumcisions are performed by mid-level staff using the MOVE model, or for use by private practitioners who have basic surgical skills and wish to add circumcision services to their practice. Because of the potential need for intraoperative and post-operative suturing, the procedure is not suitable for rural clinics that lack a provider skilled in basic surgical techniques.

\section{Study limitations}

This study was non-blinded and was performed at a single centre. The estimated blood loss was subjectively estimated by the surgeons. There was no independent, objective measure of wound healing outcomes. Rather, these outcomes were assessed by the three different physicians, with close collaboration. Given the high follow-up rates, long opening hours of the primary healthcare clinic where the study was conducted, and the easy availability of doctors via cell phone, we think it unlikely that any adverse events were missed. Finally, the costs of expendable materials were underestimated in the Unicirc group, because of the unanticipated bleeding complications.

\section{Conclusions}

This study has important implications for the scale-up of VMMC services. Excising the foreskin after applying the Unicirc instrument for $5 \mathrm{~min}$ and sealing the wound with cyanoacrylate tissue adhesive in adults is quicker, easier to learn, has superior cosmetic results and is potentially safer than open surgical VMMC. Further studies should be conducted with the optimised device. Use of this new method should greatly facilitate scale-up of mass circumcision programmes.

Author contributions. P S Millard was the lead author and made substantial contributions to conception and design, acquisition of data, analysis and interpretation of data; drafting the article and revising it critically for important intellectual content and final approval of the version to be published. H R Wilson and C Anaso participated in data collection, data analysis and drafting the article. N D Goldstuck participated in data collection and drafting the article. All authors approved the final version and agreed to publication.

Acknowledgements. We thank Drs Justin Shenje, Senzo Ntshalintshali, Siyabonga Nhlumbini and Zainul Parker for performing the circumcisions. Drs Cyril and Elisabeth Parker, Sheena Soudien, Sindiswa Njaba, Sandra Ndimangele, Simone Harris and the rest of the staff at Simunye Primary Health Care assured the success of the study through their hard work and diligence.

Conflict of interest. This study was supported by Simunye Primary Health Care. No funding bodies played any role in the design, writing, or decision to publish this manuscript. 
Table 3. Adverse events

\begin{tabular}{|c|c|c|c|}
\hline & $\begin{array}{l}\text { Unicirc/ } \\
\text { adhesive } \\
(N=100) \\
n \text { and } \%\end{array}$ & $\begin{array}{l}\text { Open } \\
\text { surgical } \\
(N=50) \\
n(\%)\end{array}$ & $p$-value \\
\hline $\begin{array}{l}\text { Serious post-operative } \\
\text { complication }\end{array}$ & 0 & 0 & - \\
\hline \multicolumn{4}{|l|}{ Post-operative bleeding } \\
\hline Mild (dressing only) & 4 & $1(2)$ & 0.25 \\
\hline Moderate (sutured) & 10 & $2(4)$ & \\
\hline Haematoma & 4 & 0 & 0.15 \\
\hline $\begin{array}{l}\text { Post-operative infection } \\
\text { (antibiotic required) }\end{array}$ & 10 & $6(12)$ & 0.71 \\
\hline \multicolumn{4}{|l|}{$\begin{array}{l}\text { Wound disruption at } 2 \text { days } \\
\text { (cm length) }\end{array}$} \\
\hline$<2$ & 2 & $1(2)$ & 1 \\
\hline$>2$ & 0 & 0 & \\
\hline \multicolumn{4}{|l|}{$\begin{array}{l}\text { Wound disruption at } 1 \text { week } \\
\text { (cm length) }\end{array}$} \\
\hline$<2$ & 6 & $1(2)$ & 0.15 \\
\hline$>2$ & 2 & 0 & \\
\hline \multicolumn{4}{|l|}{$\begin{array}{l}\text { Wound disruption at } 2 \text { weeks } \\
\text { (cm length) }\end{array}$} \\
\hline$<2$ & 8 & $2(4)$ & 0.27 \\
\hline$>2$ & 1 & 0 & \\
\hline
\end{tabular}

\section{Table 5. Doctors' survey}

\begin{tabular}{ll}
\hline & $\begin{array}{l}\text { Generalist physicians } \\
(N=4)\end{array}$ \\
\hline Circumcisions performed prior to study, & \\
median (range) & $150(10-200)$ \\
Surgical & $0(0-10)$ \\
Unicirc & \\
Ease of performance, $n(\%)$ & 0 \\
Unicirc much easier & $4(100)$ \\
Unicirc easier & 0 \\
Neutral & 0 \\
Surgical easier & 0 \\
Surgical much easier & \\
Method of preference, $n(\%)$ & $2(50)$ \\
Strongly prefer Unicirc & $2(50)$ \\
Prefer Unicirc & 0 \\
Neutral & 0 \\
Prefer surgical & $1(25)$ \\
Strongly prefer surgical & \\
Glove perforations during the study, $n(\%)$ & \\
0 & \\
1 & \\
2 & \\
&
\end{tabular}

Table 4. Post-operative outcomes

\begin{tabular}{|c|c|c|c|}
\hline & $\begin{array}{l}\text { Unicirc/ } \\
\text { adhesive } \\
(N=100)\end{array}$ & $\begin{array}{l}\text { Open } \\
\text { surgical } \\
(N=50)\end{array}$ & $p$-value \\
\hline \multicolumn{4}{|l|}{$\begin{array}{l}\text { Pain (10-point scale), } \\
\text { mean }( \pm S D)\end{array}$} \\
\hline In first $24 \mathrm{~h}$ & $4.2( \pm 2.7)$ & $3.1( \pm 2.4)$ & 0.01 \\
\hline At $48 \mathrm{~h}$ visit & $0.7( \pm 1.6)$ & $1.2( \pm 2)$ & 0.04 \\
\hline \multicolumn{4}{|l|}{ Wound fully healed, $n(\%)$} \\
\hline At 2 weeks & 0 & 0 & \\
\hline At 4 weeks & $89(90.8)$ & $49(98)$ & 0.1 \\
\hline $\begin{array}{l}\text { Sexually active at } 4 \text { weeks, } \\
n(\%)\end{array}$ & $22(22)$ & $6(12)$ & 0.14 \\
\hline \multicolumn{4}{|l|}{ Satisfaction, $n(\%)$} \\
\hline Very satisfied & $78(79.6)$ & $40(80)$ & \\
\hline Satisfied & $15(15.3)$ & $8(16)$ & \\
\hline Not satisfied & $5(5.1)$ & $2(4)$ & 0.9 \\
\hline \multicolumn{4}{|l|}{ Recommendation, $n(\%)$} \\
\hline Recommend highly & $91(92.9)$ & $48(96)$ & 0.46 \\
\hline Recommend & $4(4)$ & $1(2)$ & \\
\hline Not recommend & $3(3.1)$ & $1(2)$ & \\
\hline \multicolumn{4}{|l|}{ Cosmetic results, $n(\%)$} \\
\hline Regular & $79(80.6)$ & $20(40)$ & $<0.001$ \\
\hline Irregular & $12(12.2)$ & $8(16)$ & \\
\hline Scalloped & $7(7.1)$ & $22(44)$ & \\
\hline
\end{tabular}

Table 6. Post-study case series of subsequent Unicirc circumcisions $(N=50)$

\begin{tabular}{ll}
\hline Intraoperative suturing, $n$ & 0 \\
Blood loss (ml), median & 1.5 \\
Operative time (min), median & 9 \\
Complete follow-up, $n$ (\%) & $50(100)$ \\
Serious post-operative complication, $n$ & 0 \\
Post-operative bleeding, $n(\%)$ & \\
$\quad$ Mild (dressing only) & 0 \\
$\quad$ Moderate (sutured) & $1(2)$ \\
Haematoma, $n$ (\%) & $1(2)$ \\
Post-operative infection (antibiotic-treated), & $2(4)$ \\
$n$ (\%) & \\
$\begin{array}{l}\text { Wound disruption at any point in time } \\
\text { (cm length), } n \text { (\%) }\end{array}$ & \\
$\quad<2$ & \\
$>2$ &
\end{tabular}




\section{References}

1. Siegfried N, Muller M, Deeks JJ, Volmink J. Male circumcision for prevention of heterosexual acquisition of HIV in men. Cochrane Database Syst Rev 2009;(2):CD003362. [http://dx.doi org/10.1002/14651858.CD003362.pub2]

2. World Health Organization, UNAIDS, Joint Strategic Action Framework to Accelerate the Scale-up of Voluntary Medical Male Circumcision for HIV Prevention in Eastern and Southern Africa, 20122016. Geneva: WHO, 2011. http://www.unaids.org/en/media/unaids/contentassets/documents/ unaidspublication/2011/JC2251_Action_Framework_circumcision_en.pdf (accessed 22 November 2013)

3. Reed JB, Njeuhmeli E, Thomas AG, et al. Voluntary medical male circumcision: An HIV prevention priority for PEPFAR. J Acquir Immune Defic Syndr 2012;60(Suppl 3):S88-S95. [http://dx.doi. org/10.1097/QAI.0b013e31825cac4e]

4. Njeuhmeli E, Forsythe S, Reed J, et al. Voluntary medical male circumcision: Modeling the impact and cost of expanding male circumcision for HIV prevention in eastern and southern Africa. PLoS Med 2011;8(11):e1001132. [http://dx.doi.org/10.1371/journal.pmed.1001132]

5. Malan M. PrePex could save many lives in SA - with traditional leaders' help. Mail and Guardian. 18 June 2013. http://mg.co.za/article/2013-06-18-prepex-will-save-many-lives-in-sa-with-traditionalleaders-help (accessed 22 November 2013).

6. Bailey RC, Egesah O, Rosenberg S. Male circumcision for HIV prevention: A prospective study of complications in clinical and traditional settings in Bungoma, Kenya. Bull World Health Orgar 2008;86:669-677. [http://dx.doi.org/S0042-96862008000900010]

7. Millard PS, Wilson HR, Veldkamp PJ, Sitoe N. Rapid, minimally invasive adult voluntary male circumcision: A randomised trial. S Afr Med J 2013 2013;103(10):736-742. [http://dx.doi.org/10.7196 SAMJ.6856
8. World Health Organization. Framework for Clinical Evaluation of Devices for Adult Male Circumcision. Geneva: WHO, 2011. http://apps.who.int//iris/bitstream/10665/75954/1/9789241504355_eng.pdf (accessed 31 May 2013).

9. World Health Organization. Manual for Male Circumcision Under Local Anaesthesia. Geneva: WHO, 2009. http://www.who.int/hiv/pub/malecircumcision/who_mc_local_anaesthesia.pdf (accessed 31 May 2013).

10. Millard PS. Circumcision - what's wrong with plastic rings? S Afr Med J 2012;102(3):126-128.

11. Duffy K, Galukande M, Wooding N, Dea M, Coutinho A. Reach and cost-effectiveness of the PrePex device for safe male circumcision in Uganda. PLoS One 2013;8(5):e63134. [http://dx.doi.org/10.1371/ journal.pone.0063134]

12. Mutabazi V, Kaplan SA, Rwamasirabo E, et al. HIV prevention: Male circumcision comparison between a nonsurgical device to a surgical technique in resource-limited settings: A prospective, randomized, nonmasked trial. J Acquir Immune Defic Syndr 2012;61(1):49-55. [http://dx.doi. org/10.1097/QAI.0b013e3182631d69]

13. Obiero W, Young MR, Bailey RC. The PrePex device is unlikely to achieve cost-savings compared to the forceps-guided method in male circumcision programs in sub-Saharan Africa. PLoS One 2013;8(1):e53380. [http://dx.doi.org/10.1371/journal.pone.0053380]

14. World Health Organization. Considerations for Implementing Models for Optimizing the Volume and Efficiency of Male Circumcision Services. Geneva: WHO, 2010. http://www.malecircumcision.org/ programs/documents/mc_MOVE_2010_web.pdf (accessed 22 November 2013).

Accepted 5 November 2013. 